\title{
New 2019 Risk-Targeted Ground Motions for Spectral Design Criteria in Indonesian Seismic Building Code
}

\author{
I Wayan Sengara ${ }^{1 *}$, Masyhur Irsyam ${ }^{1}$, Indra Djati Sidi $^{1}$, Andri Mulia ${ }^{2}$, Muhamad Asrurifak ${ }^{3}$, Daniel Hutabarat ${ }^{4}$, and Windu \\ Partono $^{5}$ \\ ${ }^{1}$ Professor, Civil and Environmental Engineering Faculty, Institut Teknologi Bandung, Bandung - Indonesia \\ ${ }^{2}$ Researcher, Geotechnical Engineering Laboratory, Engineering Center for Industry, Institut Teknologi Bandung, Bandung - Indonesia \\ ${ }^{3}$ Faculty of Civil Engineering and Planning, Institut Sains dan Teknologi Nasional, Jakarta - Indonesia \\ ${ }^{4}$ UC Berkeley College of Engineering, California. \\ ${ }^{5}$ Civil Engineering Department, Diponegoro University.
}

\begin{abstract}
Indonesia has followed development of new seismic design criteria in the new seismic building codes, from hazard-based in the former SNI-03-1726-2002 to the current risk-based SNI-1726-2012. The major changes in SNI-1726-2012 are using Risk-Targeted Maximum Considered Earthquake (MCER) Spectral Response Acceleration maps. Five years later (2017), the seismic hazard maps have been updated adopting the most recent data and current state of knowledge in probabilistic and deterministic seismic hazard assessment methodologies. To establish the New 2019 Risk Targeted Ground Motion (RTGM) of spectral acceleration $\left(S_{s}\right.$ and $\left.S_{1}\right)$, and risk coefficients $\left(C_{R S}\right.$ and $\left.C_{R 1}\right)$, for both short $(T=0.2 s)$ and 1 -second $(T=1 s)$ periods, respectively have been developed based on the 2017 Indonesian hazard maps. The RTGM was calculated as the spectral value resulting in $1 \%$ probability of building collapse in 50 years through numerical integration of hazard curves and structural capacity. The log-normal standard deviation $(\beta)$ of the structural capacity envelope has been revised from 0.70 to 0.65 . This paper presents the new resulted RTGM maps. Furthermore, the paper also presents revision of seismic amplification factors for $0,0.2$, and 1 second periods $\left(F_{p G A}, F_{a}\right.$, and,$\left.F_{v}\right)$ to generate ground surface maximum and design spectra associated with the siteclassifications.
\end{abstract}

\section{Introduction}

Many areas in Indonesia are highly potential to seismic hazards as it is located within the convergence of four tectonic plates: Eurasian, Indian-Australian, Pacific and the Philippine plates. The interaction between these plates has turned many areas, for example, Sumatra, Java, Sulawesi, Nusa Tenggara, and Papua into risky spot.

In fact, almost everyday relatively small earthquake occurs in Indonesia. Several relatively large to very large earthquakes have occurred in the last two decades that have caused the failure of the structure and the death of people.

It infers us to enhance the regulation continously considering that structural design under earthquake must be the vital factor of the future building demands. Significant effort must be pointed to the development of the seismic design map regulation with adopting the quality improvement of new seismic source data and using the most current methodology.

Prior to 2012, the seismic design criteria for buildings in Indonesia (SNI-1726-2002) is out of date after significant earthquakes hit Indonesia during the year 2000 to 2010 . Moreover, the map was purely calculated based on seismic hazard and using ground motion spectral accelerations of $10 \%$ probability of being exceeded (PE) in 50 years or having 500 years of return period.

Eventually, Indonesia has replaced successfully the previous code by SNI-1726-2012 providing ground motion values having a $2 \%$ probability of being exceeded in 50 years or having spectral acceleration for 2475 years of return period.

The significant issues of this updated code are not only changing the return period but also accounting uncertainty of a collapse capacity of structures. A method, which determine the risk has been used by implementing direct integral to calculate risk-targeted ground motions (RTGM) of $1 \%$ probability of building collapse in 50 years that is derived by integrating $2 \% \mathrm{PE}$ in 50 years hazard curves of the New 2010 Indonesian seismic hazard with fragility curve of Indonesian buildings defined to have $10 \%$ probability of collapse. This follow the seismic design criteria developed for United States of America by Luco et al. (2007), that has been adopted in ASCE-SEI-7-10. Furthermore, the SNI1726-2012 adopted three seismic design maps for response spectral at $\mathrm{T}=0 \mathrm{~s}(\mathrm{PGA})$, short $(\mathrm{T}=0.2 \mathrm{~s})$, and long $(\mathrm{T}=1 \mathrm{~s})$ periods refer to ASCE-SEI-7-10.

Five years later after launching the 2012 code (2017), the seismic hazard maps have been enhanced. The 2017 seismic hazard maps are updated by considering as follows:

\footnotetext{
corresponding author: wayansengara@si.itb.ac.id
} 
1. Quality improvement with updating, adding, finding, and identifying new seismic sources of geological, geodetic, seismology \& instrumentation, ground motion prediction equation, and seismic hazard analysis aspects.

2. New information regarding the identification of active faults with a significant number. The information covers both active faults that have not been appropriately quantified during the preparation of the 2010 Indonesia Earthquake Hazard Map and new active faults that are quantified better based on field research through trenching, carbon dating, epicenter relocation, and strain analysis with geodetic data.

3. Availability of more topographic data with better resolution, namely SRTM-30, IFSAR, and LIDAR topographic data

4. The use of a more complete and more accurate earthquake catalogue by updating the earthquake catalogue until 2016 that relocated with 3D-speed models, and comprehensive earthquake background source.

In order to find out the effect of the enhancement, this paper tend to present the comparison of design spectra, ground amplification, RTGM and risk coefficient between SNI-1726-2012 and proposed SNI-1726-2019 at several cities in Indonesia.

\section{New 2017 Probabilistic Maximum Considered Earthquake Hazard of Indonesia}

The new 2017 Indonesian seismic hazard maps have been produced and published using concepts deterministic (Deterministic Seismic Hazard Analysis/DSHA) and probabilistic (Probabilistic Seismic Hazard Analysis/PSHA). The Indonesian seismic hazard maps 2017 is presented in the form of peak ground acceleration (PGA) and spectral response accelerations for short period $(0.2 \mathrm{sec})$ and for 1 -second period. For the purposes of RTGM development, a combination of PSHA with 2,500-year return period and $84^{\text {th }}$ percentile DSHA have been conducted.

The DSHA was conducted in four stages (Kramer, 1996); (1) identification and characterization of all earthquake sources capable of producing significant ground motion at the site including source locations and geometry, focal mechanisms, earthquake history, and earthquake recurrence relations, (2) determination of earthquake parameters for certain scenario such as maximum magnitude and closest distance to the site, (3) selection of the controlling earthquake that is generally expressed in term of ground motion parameters, (4) calculation of seismic design parameters such as peak acceleration, peak velocity, and response spectrum ordinates that is usually selected as the worst case scenario.

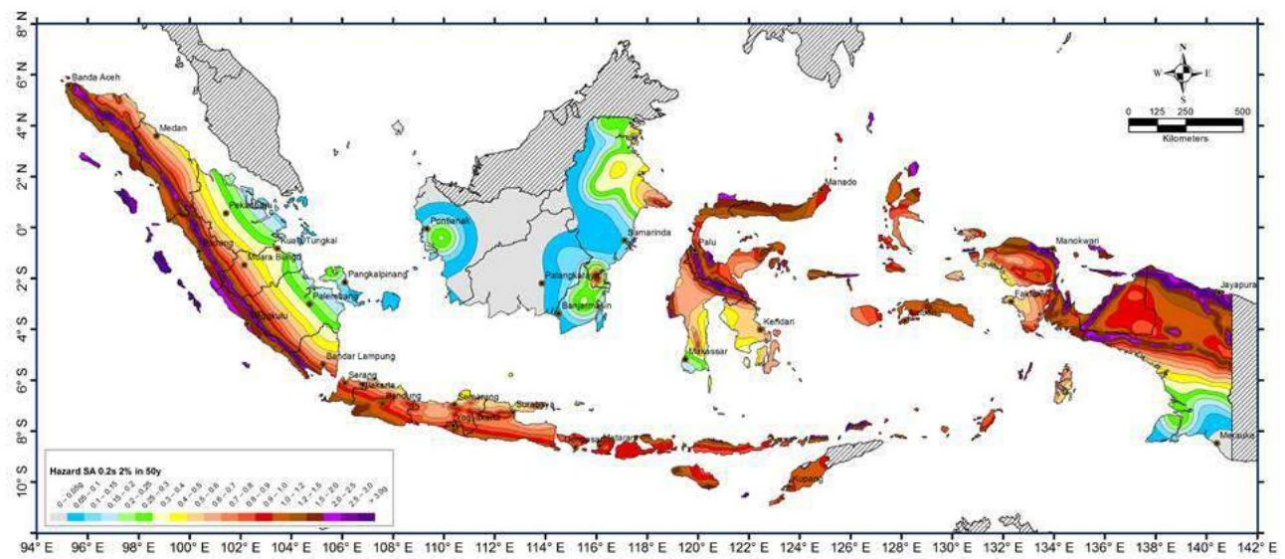

(a)

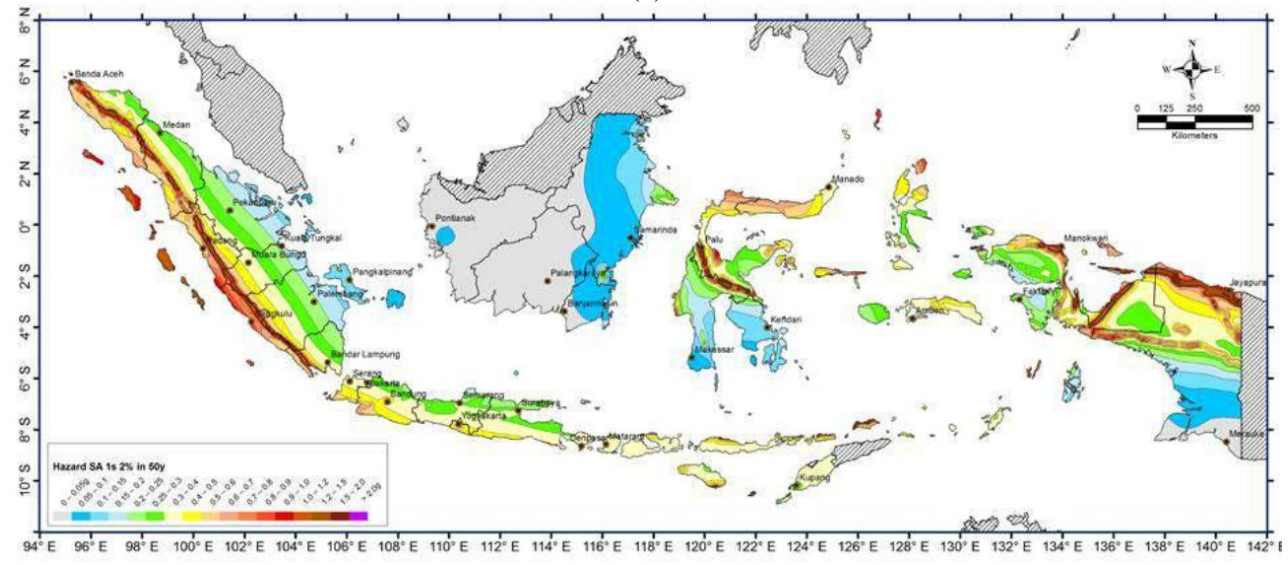

(b)

Fig. 1. (a) Map of Spectral Acceleration at $\mathrm{T}=0.2 \mathrm{~s}$ of Indonesia for $2 \%$ probability of exceedance in 50 year, and (b) Map of Spectral Acceleration at $\mathrm{T}=1.0 \mathrm{~s}$ of Indonesia for $2 \%$ probability of exceedance in 50 year (Irsyam et al., 2017) 
The PSHA considers earthquake magnitude distribution, distances distribution to earthquake sources, and ground accelerations. Following formulation shows annual probability value of maximum ground acceleration, $q_{y}$, due to earthquakes with magnitude, $M$, more significant than the specific value of ' $y$ ' (Cornell, C.A., 1968)

$$
q_{y}=P\left(\mathrm{Y}_{\max }>y\right)
$$

The higher value of ' $y$ ' implies a lesser value of $\mathrm{q}_{\mathrm{y}}$, and expected return period, $\mathrm{T}$, from this earthquake can be derived through the following equation:

$$
T=\frac{1}{q_{y}}
$$

Since this method is based on the probabilistic approach, periodic update due to earthquake events that continuously occur need to be made. Indonesia, through the National Center for Earthquake Studies (PuSGeN), updated the seismic hazard maps in 2017. The maps are defined as Probabilistic Maximum Considered Earthquake (MCE) which is a predicted maximum acceleration having a $2 \%$ probability of being exceeded in 50 years ( 2475 years of return period) for short $(\mathrm{T}=0.2 \mathrm{~s})$ and long $(\mathrm{T}=1.0 \mathrm{~s})$ periods, as presented in Fig.1.

The critical change in the new 2017 Indonesian seismic hazard map is the revised active fault database as the latest research results by the PuSGeN, (Irsyam et al., 2017). It includes the addition of newly identified active faults, revisions of the locations of previously known active fault traces, as well as improved estimates of maximum magnitudes and slip rates. The historical earthquake events used magnitude, $M_{w}, \geq 4.5$ occurring in and around Indonesia from 1900 to August 2016 are merged from many sources such national and international institutions with the total number of earthquakes more than 51,000 events. This earthquake events have been relocated and named the PuSGeN catalog.

The GMPE that also updated for the development of the Indonesian seismic hazard map for 2017, such as for shallow crustal fault and shallow background sources models has been used the GMPE the latest study that is: Boore-Atkinson NGA West-2 (2014), CampbellBozorgnia NGA West-2 (2014) and Chiou-Youngs NGA West-2 (2014), which is an update from GPME 2008 by its researchers, respectively. As an addition, the new GMPE such as BC Hydro (Abrahamson et al., 2014) also used for the subduction source model. The above changes which are input parameters for seismic hazard analysis (SHA) have affected the hazard value, especially in areas where there are additional faults. This new hazard map has also been analyzed using two software namely PSHA from USGS and OpenQuake from Global Earthquake Model (GEM), where the hazard maps previously only use USGS software.

\section{Risk Targeted Ground Motion}

Several studies show that earthquake resistance structures, which were designed using a similar hazard, give different response or risk (e.g., Liel et al., 2015; Luco et al., 2007; and Porter et al., 2007). The behavior of structure resistance is random following lognormal distribution (Luco et al., 2007).

The use of sections to divide the text of the paper is optional and left as a decision for the author. Where the author wishes to divide the paper into sections the formatting shown in Table 2 should be used. In general, the following equation shows the probability of failure from the structure (or risk) caused by the earthquake (Luco et al., 2007):

$$
\text { Risk, } \mathrm{Pf}=\int_{0}^{\infty} f_{R} \text { (a) } f_{E_{m}}(\mathrm{SA}>\mathrm{a}) \mathrm{da}
$$

$$
f_{R}(a)=\frac{1}{a \beta \sqrt{2 \pi}} \exp \left[-\frac{(\ln a-(\ln (\mathrm{RTGM})+1.28 \beta))^{2}}{2 \beta^{2}}\right]
$$

Where $f_{E_{m}}(\mathrm{a})$ and $f_{R}(\mathrm{a})$ are hazard curve and structural capacity against the earthquake load, respectively, which are presented in Error! Reference source not found.

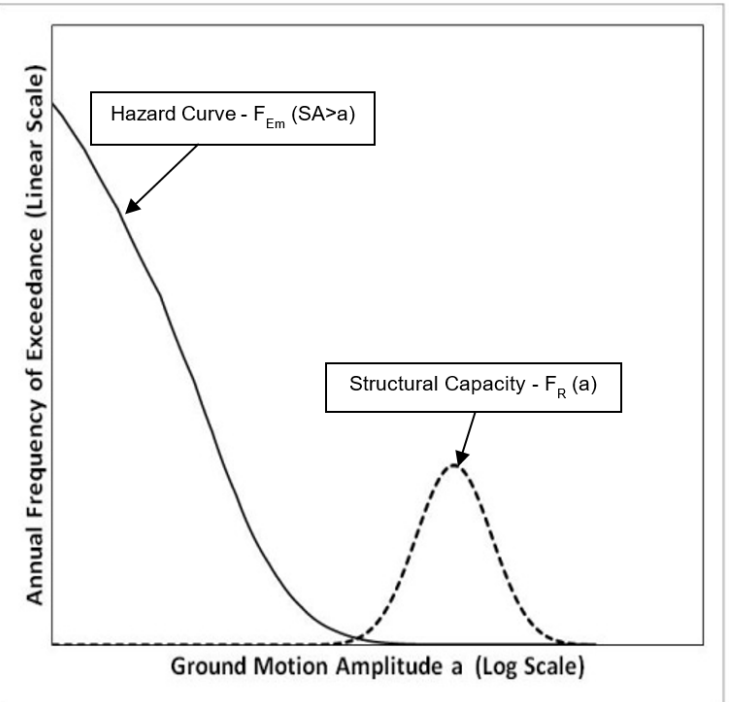

Fig. 2. Illustration of Hazard Curve and Structural Capacity Curve

\subsection{Notes on Ground Motion Maximum Direction of Response}

As described in Whittaker (2009) and FEMA/NEHRP, most GMPEs are defined in terms of average (geometric mean) horizontal response. Structures need to be designed to resist ground motions in maximum direction of response. Maximum direction was adopted as the ground motion intensity parameter for use in seismic design for the purpose of explicit consideration of directional effects. It has been identified through many researches that maximum response in the horizontal plane is greater than average response by a certain amount. This response also varies with period. As described in Huang et al. (2007) that maximum response may be reasonably estimated by factoring average response by period dependent factors.

Additionally, the collapse of structure occured due to the effect of two direction horizontal movement (Kicher, 
2009). This issue has been accomodated with applying directionality factor for each period of interest. The current seismic building code of Indonesia adopts directionality factors of 1.05 and 1.15 for short $(\mathrm{T}=0.2$ $\mathrm{sec})$ and long $(\mathrm{T}=1.0 \mathrm{sec})$ periods, respectively. Since this factors could be considered as general for maximum direction of response of structures which are independent of geographical condition.

Whilst FEMA/NEHRP and Whittaker (2009) suggest the direcionality factors of 1.1 at short periods and 1.3 at a period of 1.0 second. These factors are adopted in this study.

\subsection{Development of RTGM Computation for Indonesia}

Since Indonesia has lesser data of reliable motion records, then the structural capacity curve and the lognormal-standard-deviation $(\beta)$ is not able to be defined explicitly. Analysis and recommendations on representative $\beta$ of Indonesian buildings have been conducted through hazard analysis and probability-based safety factors by Sidi I.D. (2011). The analysis identified inherent variability of concrete compressive strength and steel reinforcement tension capacity, simplification of actual field conditions representing random phenomena in the design formulation, and random human errors through reliability analysis in the derivation of the fragility function that is considered to be representative for the Indonesian condition. The analysis suggests that $\mathrm{b}$-values for Indonesia is in the range of 0.65 to 0.7 . For the development of SNI-1726-2012, a relatively high value of $\beta=0.7$ was adopted. While for the new proposed code, the representative value was drawn in an experts consensus held in January 2018, agreeing to adopt the value of 0.65 .

Considering a site-specific hazard curve corrected by the directivity factor, $\gamma(a)$, Equation 3 can be derived as follows:

$$
P_{F}=\int_{0}^{\sim} \gamma(a) \frac{1}{a \beta \sqrt{2 \pi}} \exp \left[-\frac{(\ln a-(\ln (\mathrm{RTGM})+1.28 \beta))^{2}}{2 \beta^{2}}\right] \mathrm{d} a
$$

According to the equation above, the RTGM can be directly computed through numerical integration and iterative process when the ground motion spectral value, $a$, resulting in a $1 \%$ probability of failure, $P f$, in 50 years as presented in Fig. 3 below. The flow chart below is an enhancement from the work of Sengara, et. al. (2015).

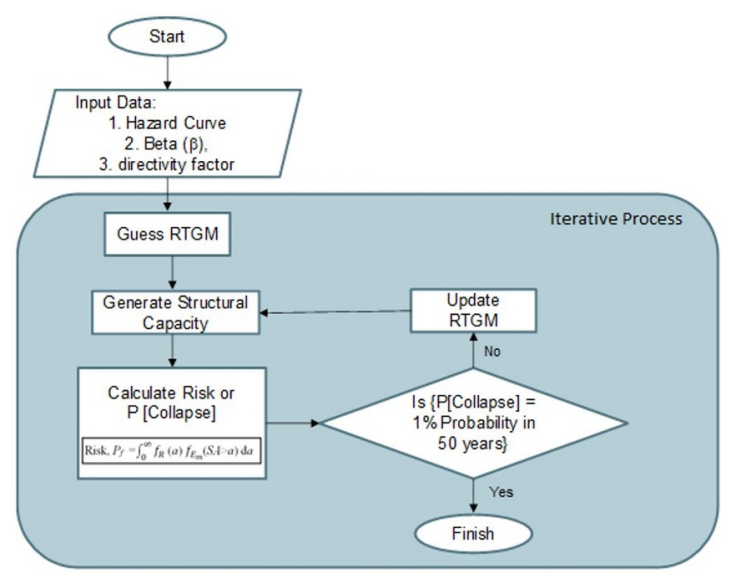

Fig. 3. Flow Chart of RTGM Calculation

A Risk Coefficient is a ratio of RTGM with MCE being corrected by the directivity factor and formulated as follows:

$$
C_{R T}=\frac{R T G M_{T}}{M C E_{T} * D F_{T}}
$$

where DF is directivity factor, and T denotes the interest spectral period.

\subsection{Results of RTGM Maps}

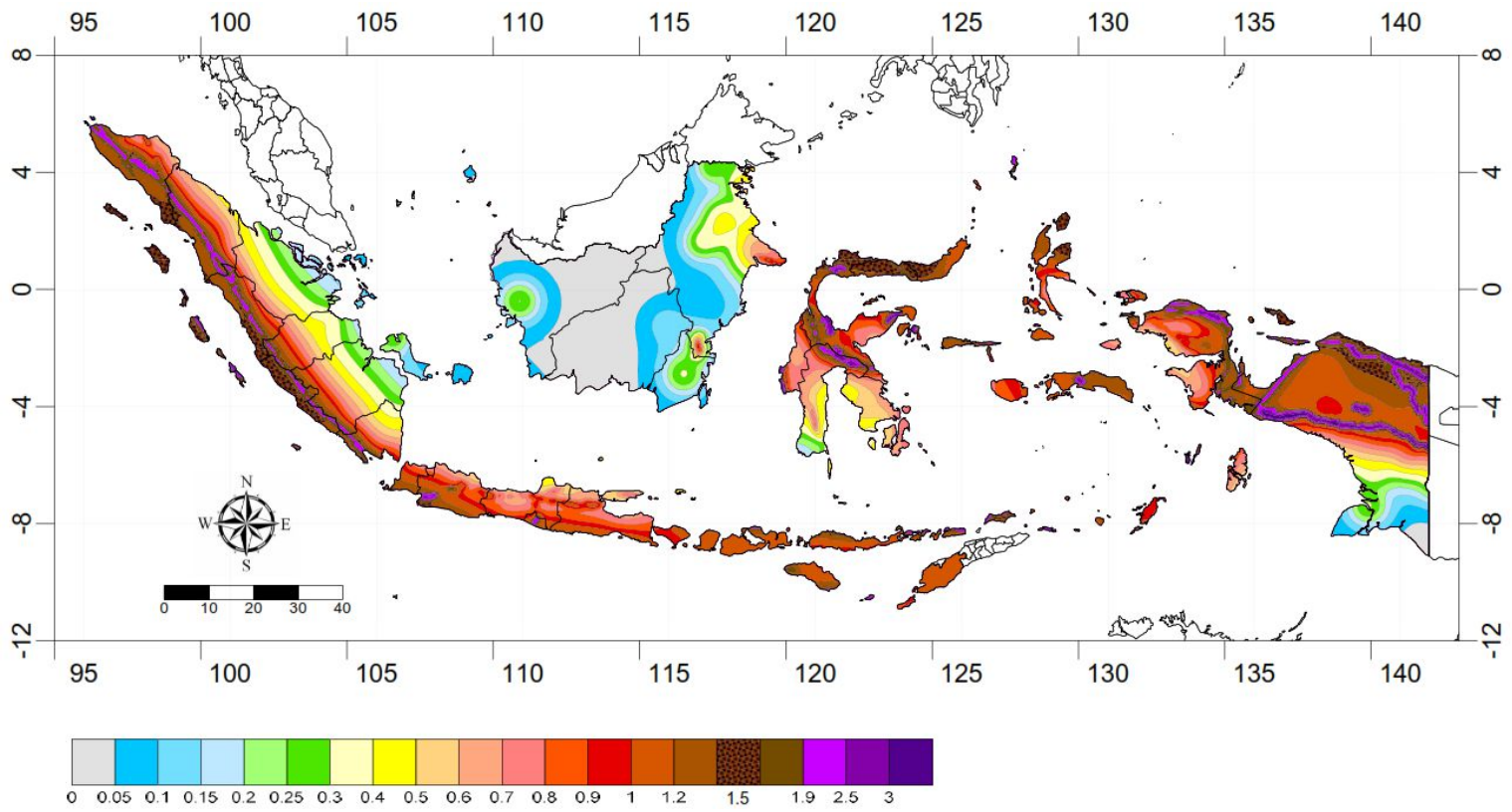

(a) 

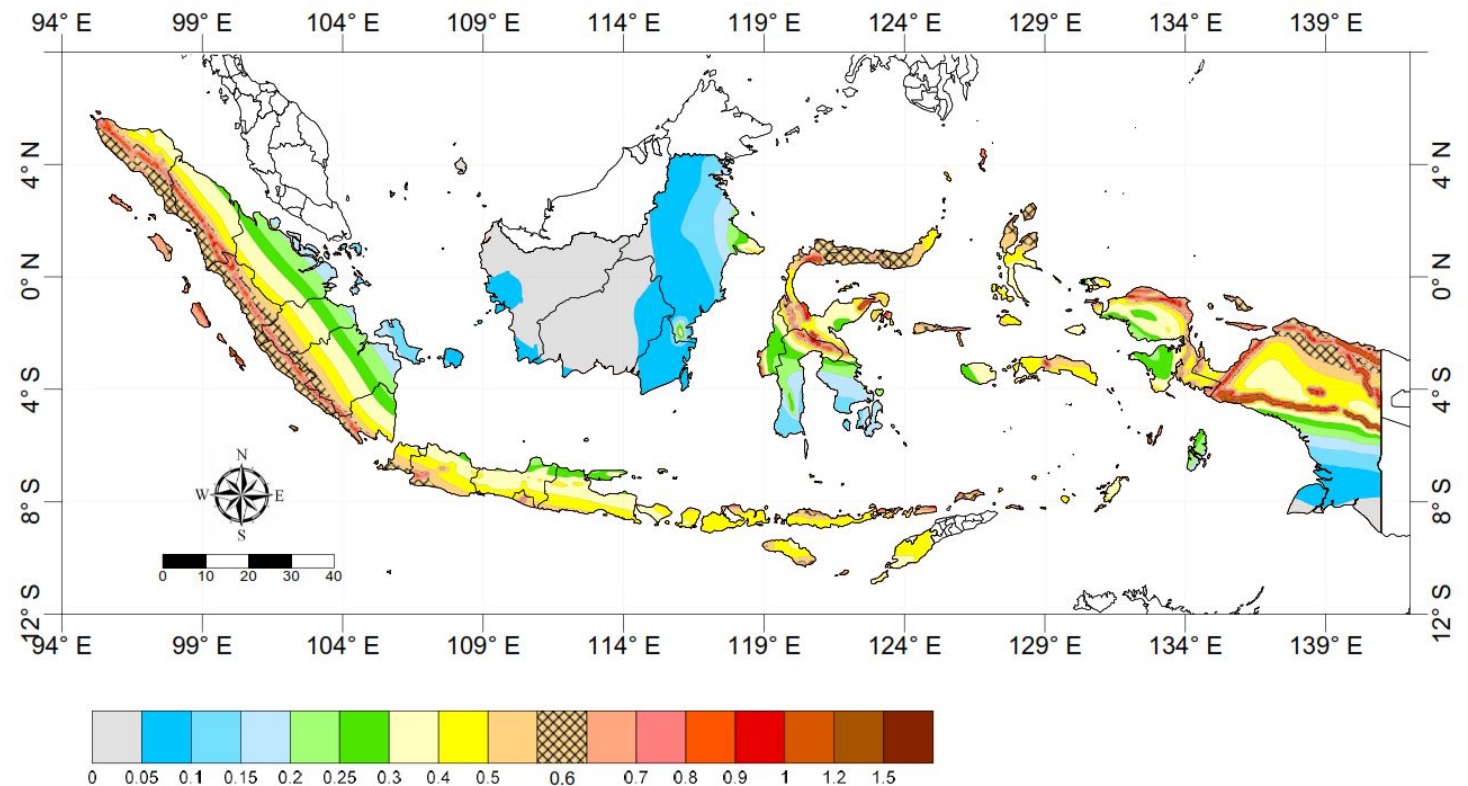

(b)

Fig. 4. (a) Ss Risk-Targeted Maximum Considered Earthquake $\left(\mathrm{MCE}_{\mathrm{R}}\right)$ Ground Motion Parameter for Indonesia for $0.2 \mathrm{~s}$ Spectral Response Acceleration (5\% of Critical Damping), Site Class B; (b) $S_{l}$ Risk-Targeted Maximum Considered Earthquake (MCER) Ground Motion Parameter for Indonesia for $1.0 \mathrm{~s}$ Spectral Response Acceleration (5\% of Critical Damping), Site Class B.

Fig. 4(a) and Fig. 4(b) show RTGM maps for Indonesia at $0.2 \mathrm{~s}$ and 1.0 spectral response acceleration, respectively, Site Class B (5\% of critical damping). While Fig. 5 shows Risk Coefficient maps of $C R s$ (correspond to spectral values at $\mathrm{T}=0.2 \mathrm{~s}$ ) and $C R_{l}$ (correspond to spectral values at $\mathrm{T}=1.0 \mathrm{~s}$ ).

Evaluating $C R_{l}$ values as shown at Fig. 6 (a), it is identified that $C R_{1}$ values for most $(91.97 \%, 5870$ out of total 6326) of the Indonesian districts are in the range of 0.9 to 1.1 and about $8.02 \%$ in the range of 0.7 to 0.9 . Like the $C R_{l}$, the distribution on values of $C R s$ shows $92.81 \%$ of the Indonesian districts are in the range of 0.9 to 1.1 and about $9.96 \%$ in the range of 0.7 to 0.9 . The distribution of $C R s$ value can be seen in Fig. 7 (b). Those percentages are not significantly change with previous study, Sengara et al., 2015. Comparison and changes RTGM and risk coefficient (CR) values (at $\mathrm{T}=0.2 \mathrm{~s}$ and $\mathrm{T}=1.0 \mathrm{~s}$ ) between SNI-1726-2012 and proposed SNI1726-2019 for 17 cities in Indonesia shown in Table 1 to Table 2 and Fig. 8 to Fig. 9.

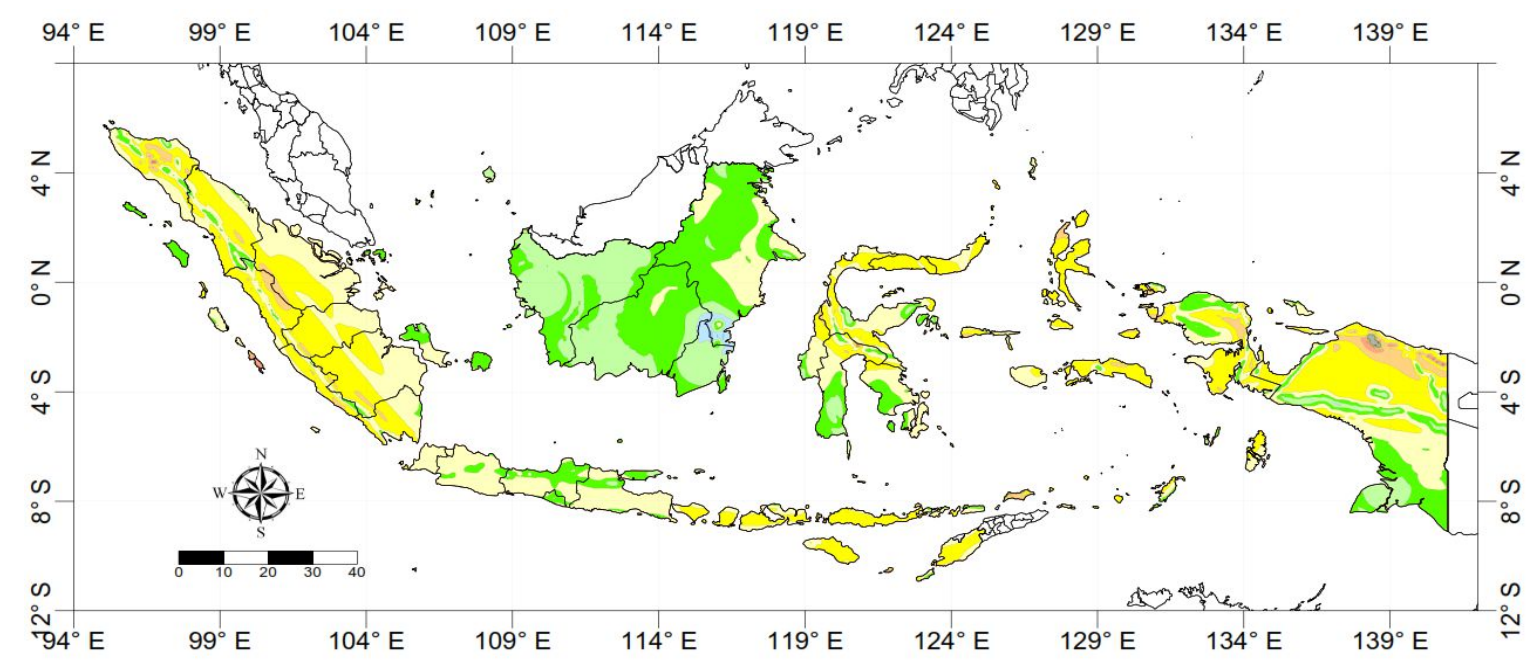




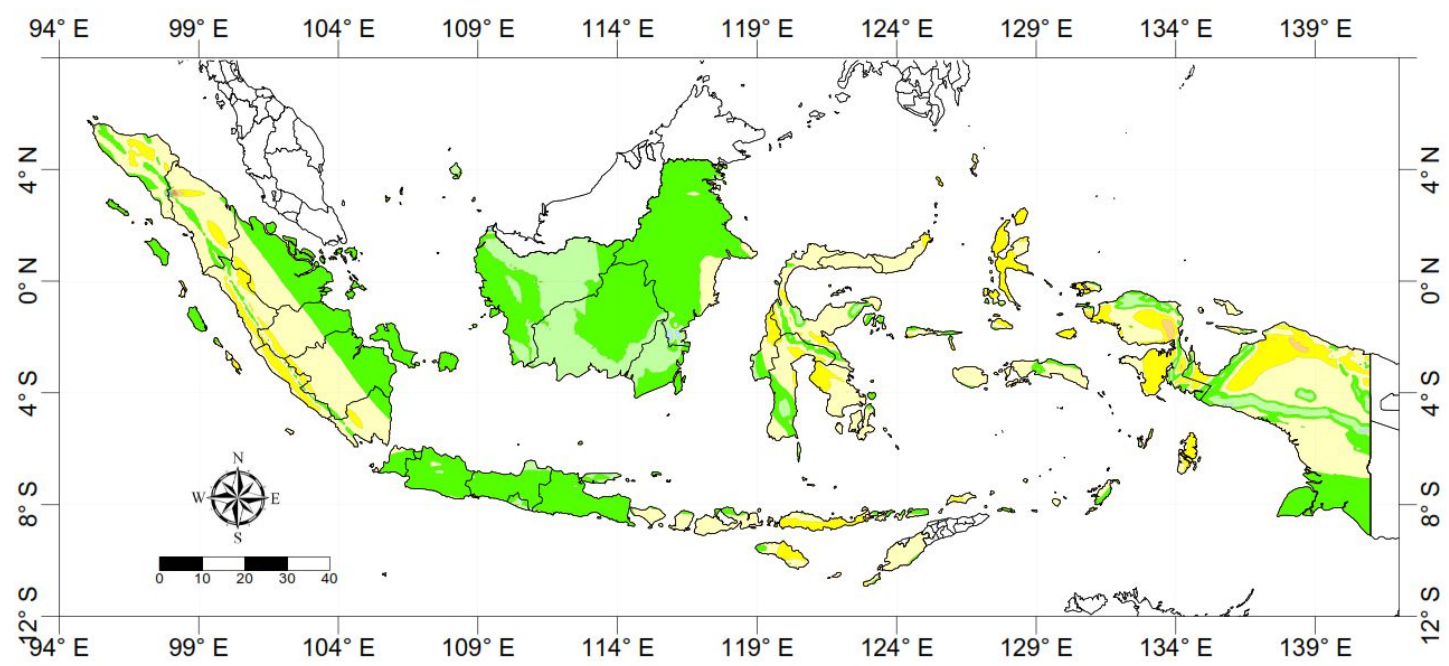

(b)

Fig. 5. (a) Map of CRs (CR value correspond to spectral values at 0.2 second period) and (b) $\mathrm{CR}_{1}$ (CR value correspond to spectral values at 1.0 second period)

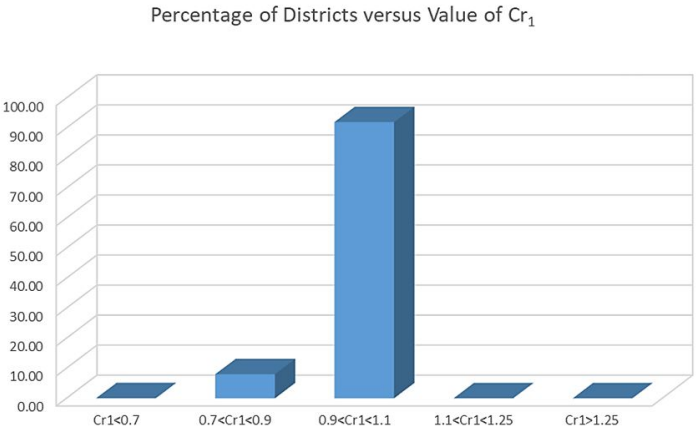

(a)

Percentage of Districts versus Value of $\mathrm{Cr}_{s}$

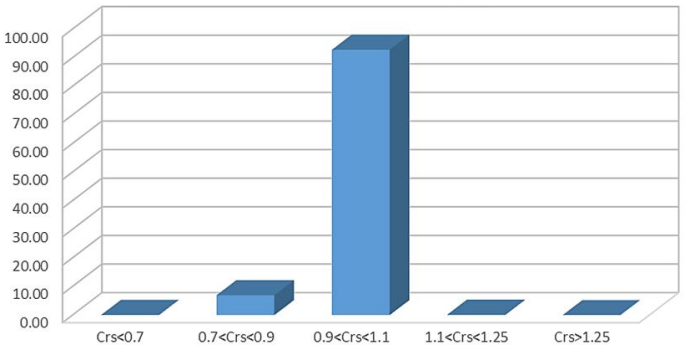

(b)

Fig. 6. (a) Distribution of $\mathrm{CR}_{1}$ values; (b) Distribution of $\mathrm{CR}_{\mathrm{s}}$ values; in percentage (total district: 6326)

\section{Revision on Spectral Amplification Factors}

Separately from the updates to the RTGM maps, the site coefficients used to adjust the mapped values for soil properties have also been updated for the SNI-17262019. In both the SNI-1726-2012 and SNI-1726-2019, the ground motion maps are for an average shear wave velocity at small shear strains in the upper 30 meters of subsurface below a site, $\mathrm{V}_{\mathrm{s} 30}$, of $760 \mathrm{~m} / \mathrm{s}$. In order to adjust the mapped RTGM $\left(\mathrm{S}_{\mathrm{S}}\right.$ and $\left.\mathrm{S}_{1}\right)$ and $\mathrm{MCE}_{\mathrm{G}}(\mathrm{PGA})$ values to other site classes, the site coefficients $F_{a}, F_{v}$, and $\mathrm{F}_{\mathrm{PGA}}$ are applied to $\mathrm{S}_{\mathrm{S}}, \mathrm{S}_{1}$, and PGA, respectively.

The RTGM site coefficients ( $\mathrm{Fa}$ and $\mathrm{Fv}$ ) have changed as high as $20 \%$, for example, $\mathrm{Fv}$ is modified to 1.8 from 1.5 for SD Site Class at $\mathrm{S}_{1}=0.5 \mathrm{~g}$; Fa is modified to 1.2 from 1.0 for SC Site Class at $\mathrm{SS} \geq 1 \mathrm{~g}$; and $\mathrm{Fv}$ is modified to 0.8 from 1.0 for SC Site Class at all values of $\mathrm{S}_{1}$. The $\mathrm{MCE}_{\mathrm{G}}$ site coefficient $\left(\mathrm{F}_{\mathrm{PGA}}\right)$ has similarly increased by approximately $20 \%$ for SC Site Class and PGA $\geq 0.4 \mathrm{~g}$, and has increased by approcimately $20 \%$ to $56 \%$ for SE Site Class at PGA $\geq 0.25 \mathrm{~g}$. The ratios of updated site coefficient of $F_{a}, F_{v}$, and $F_{P G A}$ in the SNI1726-2019 divided by those in SNI-1726-2012 are summarized in Fig. 7. Please note that this modification is also under consideration that the referecne suburface rock is currenly specified as $\mathrm{BC}(\mathrm{Vs}=760 \mathrm{~m} / \mathrm{s})$, whereas previously, it is specified as Site Class B.

Evaluating short-period site coefficient $\mathrm{F}_{\mathrm{a}}$ as shown at Table 3, it is identified that coefficient of $F_{a}$ in SNI1726-2019 have slightly difference for SE site class at Ss $\geq 1.0$ than those in ASCE-7-16, for example, $F_{a}=1,1$ and 1,2 for SNI-1726-2019 and ASCE-7-16, respectively. However, similar values is shown for the coefficient of $F_{v}$ and $F_{P G A}$ in SNI-1726-2019 and ASCE-7-16. These new site amplifications are also under consideration with reference to Kircher and Associates (2015). 
Table 1. The New RTGM and $C_{R}$ values for 17 Cities in Indonesia

\begin{tabular}{|c|c|c|c|c|c|c|c|}
\hline \multirow{2}{*}{ No } & \multirow{2}{*}{ City } & \multicolumn{2}{|c|}{ Coordinates } & \multirow{2}{*}{$\begin{array}{c}\text { RTGM } \\
(\mathrm{g})\end{array}$} & $\begin{array}{c}\mathrm{RTGM}_{1.0 \mathrm{~s}} \\
(\mathrm{~g})\end{array}$ & $\mathrm{Cr}_{\mathrm{s}}$ & $\mathrm{Cr}_{1}$ \\
\cline { 3 - 7 } & & Longitude & Latitude & & & \\
\hline 1 & Aceh & 95.3 & 5.5 & 1.519 & 0.600 & 0.994 & 0.968 \\
\hline 2 & Medan & 98.7 & 3.6 & 0.644 & 0.357 & 0.998 & 0.975 \\
\hline 3 & Padang & 100.4 & -0.9 & 1.446 & 0.600 & 1.035 & 1.002 \\
\hline 4 & Palembang & 104.8 & -3.0 & 0.291 & 0.248 & 0.987 & 0.920 \\
\hline 5 & Jakarta & 106.9 & -6.2 & 0.788 & 0.381 & 0.987 & 0.945 \\
\hline 6 & Bandung & 107.6 & -6.9 & 1.194 & 0.513 & 0.928 & 0.912 \\
\hline 7 & Semarang & 110.4 & -7.0 & 0.916 & 0.392 & 0.917 & 0.903 \\
\hline 8 & Surabaya & 112.8 & -7.3 & 0.679 & 0.307 & 0.945 & 0.920 \\
\hline 9 & Balikpapan & 116.8 & -1.3 & 0.121 & 0.081 & 0.905 & 0.935 \\
\hline 10 & Pontianak & 109.3 & 0.0 & 0.150 & 0.050 & 0.878 & 0.918 \\
\hline 11 & Denpasar & 115.2 & -8.7 & 0.955 & 0.399 & 1.003 & 0.964 \\
\hline 12 & Kupang & 123.6 & -10.2 & 1.046 & 0.373 & 1.008 & 0.985 \\
\hline 13 & Makassar & 119.4 & -5.1 & 0.230 & 0.109 & 0.927 & 0.965 \\
\hline 14 & Manado & 124.8 & 1.5 & 1.058 & 0.471 & 1.001 & 0.992 \\
\hline 15 & Ambon & 128.2 & -3.7 & 1.084 & 0.391 & 1.002 & 0.972 \\
\hline 16 & Jayapura & 140.7 & -2.5 & 1.500 & 0.629 & 0.971 & 0.974 \\
\hline 17 & Manokwari & 134.1 & -0.9 & 1.500 & 0.600 & 1.046 & 0.997 \\
\hline
\end{tabular}

Table 2. Changes in the RTGM and $C_{R}$ values between SNI-1726-2012 and proposed SNI-1726-2019 for 17 Cities in Indonesia

\begin{tabular}{|c|c|c|c|c|c|c|c|}
\hline \multirow{2}{*}{ No } & \multirow{2}{*}{ City } & \multicolumn{2}{|c|}{ Coordinates } & \multirow{2}{*}{ RTGM $_{0.2 \mathrm{~s}}$} & \multirow{2}{*}{$\mathrm{RTGM}_{1.0 \mathrm{~s}}$} & $\mathrm{Cr}_{\mathrm{s}}$ & $\mathrm{Cr}_{1}$ \\
\cline { 3 - 7 } & & Longitude & Latitude & & & & \\
\hline 1 & Aceh & 95.3 & 5.5 & $+18 \%$ & $+7 \%$ & $0 \%$ & $0 \%$ \\
\hline 2 & Medan & 98.7 & 3.6 & $+19 \%$ & $+10 \%$ & $-1 \%$ & $-2 \%$ \\
\hline 3 & Padang & 100.4 & -0.9 & $+5 \%$ & $0 \%$ & $-5 \%$ & $-4 \%$ \\
\hline 4 & Palembang & 104.8 & -3.0 & $+11 \%$ & $+35 \%$ & $+6 \%$ & $+1 \%$ \\
\hline 5 & Jakarta & 106.9 & -6.2 & $+14 \%$ & $+24 \%$ & $0 \%$ & $+69 \%$ \\
\hline 6 & Bandung & 107.6 & -6.9 & $-26 \%$ & $+4 \%$ & $-5 \%$ & $-3 \%$ \\
\hline 7 & Semarang & 110.4 & -7.0 & $-9 \%$ & $+16 \%$ & $+6 \%$ & $-3 \%$ \\
\hline 8 & Surabaya & 112.8 & -7.3 & $+3 \%$ & $+19 \%$ & $-5 \%$ & $-2 \%$ \\
\hline 9 & Balikpapan & 116.8 & -1.3 & - & - & $-2 \%$ & $-3 \%$ \\
\hline 10 & Pontianak & 109.3 & 0.0 & - & - & $-7 \%$ & $0 \%$ \\
\hline 11 & Denpasar & 115.2 & -8.7 & $-2 \%$ & $+10 \%$ & $-5 \%$ & $-7 \%$ \\
\hline 12 & Kupang & 123.6 & -10.2 & $-6 \%$ & $+22 \%$ & $-1 \%$ & $-1 \%$ \\
\hline 13 & Makassar & 119.4 & -5.1 & $-39 \%$ & $-28 \%$ & $-22 \%$ & $-32 \%$ \\
\hline 14 & Manado & 124.8 & 1.5 & $+2 \%$ & $+7 \%$ & $-4 \%$ & $-7 \%$ \\
\hline 15 & Ambon & 128.2 & -3.7 & $-18 \%$ & $-15 \%$ & $-8 \%$ & $-9 \%$ \\
\hline 16 & Jayapura & 140.7 & -2.5 & $0 \%$ & $+5 \%$ & $-15 \%$ & $-7 \%$ \\
\hline 17 & Manokwari & 134.1 & -0.9 & $+3 \%$ & $+10 \%$ & $-4 \%$ & $-3 \%$ \\
\hline
\end{tabular}

Furthermore, the parameter $\mathrm{T}_{\mathrm{L}}$ was introduced in SNI-1726-2019 to provide more realistic ground motions at periods $\mathrm{T}>4 \mathrm{sec}$ that would affect the design of tall buildings. Long period transition, $\mathrm{T}_{\mathrm{L}}$, in this case is marks the transition between the constant velocity and constant displacement segments of the fourier spectrum representing a theoritical fault-rupture displacement history.

Based on several parameters that have been updated such as RTGM, spectral amplicifaction factors, and $T_{L}$ parameters, there is quite significant difference between design response spectrum adopting SNI-1726-2012 and 
SNI-1726-2019 parameters. For example, the design response spectrum of city of Padang is increase from low period $(0.2 \mathrm{~s})$ until reaches $T_{L}$ parameters $(20 \mathrm{~s})$. In long period, such $20 \mathrm{~s}$, the spectral response acceleration is decrease compared with SNI-1726-2012. Fig. 8 shown the design response spectrum difference of city of Padang and Jakarta using SNI-1726-2012 and SNI-17262019 parameters.

Table 3. Short-Period Site Coefficient, Fa (SNI-1726-2019)

\begin{tabular}{|c|c|c|c|c|c|c|}
\hline \multirow{3}{*}{ Site Class } & \multicolumn{6}{|c|}{$\begin{array}{c}\text { Mapped Risk-Targeted Maximum Considered Earthquake (MCE } \\
\text { Spectral Response Acceleration Parameter at Short Period }\end{array}$} \\
\cline { 2 - 7 } & $S_{S} \leq 0,25$ & $S_{S}=0,5$ & $S_{S}=0,75$ & $S_{s}=1,0$ & $S_{s}=1,25$ & $S_{s} \geq 1,5$ \\
\hline$S A$ & 0,8 & 0,8 & 0,8 & 0,8 & 0,8 & 0,8 \\
\hline$S B$ & 0,9 & 0,9 & 0,9 & 0,9 & 0,9 & 0,9 \\
\hline$S C$ & 1,3 & 1,3 & 1,2 & 1,2 & 1,2 & 1,2 \\
\hline$S D$ & 1,6 & 1,4 & 1,2 & 1,1 & 1,0 & 1,0 \\
\hline$S E$ & 2,4 & 1,7 & 1,3 & $1,1(1,2)^{*}$ & $0,9(1,2)^{*}$ & $0,8(1,2)^{*}$ \\
\hline
\end{tabular}

Note: *Coefficient in the parentheses ( ) is short-period site coefficient (Fa) of ASCE-7-16

Table 4. 1-Second Period Site Coefficient, Fv (SNI-1726-2019)

\begin{tabular}{|c|c|c|c|c|c|c|}
\hline \multirow{2}{*}{ Site Class } & \multicolumn{6}{|c|}{$\begin{array}{c}\text { Mapped Risk-Targeted Maximum Considered Earthquake (MCER) } \\
\text { Spectral Response Acceleration Parameter at 1-s Period }\end{array}$} \\
\cline { 2 - 7 } & $S_{I} \leq 0,1$ & $S_{I}=0,2$ & $S_{I}=0,3$ & $S_{I}=0,4$ & $S_{I}=0,5$ & $S_{I} \geq 0,6$ \\
\hline$S A$ & 0,8 & 0,8 & 0,8 & 0,8 & 0,8 & 0,8 \\
\hline$S B$ & 0,8 & 0,8 & 0,8 & 0,8 & 0,8 & 0,8 \\
\hline$S C$ & 1,5 & 1,5 & 1,5 & 1,5 & 1,5 & 1,4 \\
\hline$S D$ & 2,4 & 2,2 & 2,0 & 1,9 & 1,8 & 1,7 \\
\hline$S E$ & 4,2 & 3,3 & 2,8 & 2,4 & 2,2 & 2,0 \\
\hline
\end{tabular}

Table 5. Site Coefficient FPGA (SNI-1726-2019)

\begin{tabular}{|c|c|c|c|c|c|c|}
\hline Site Class & PGA $\leq \mathbf{0 , 1}$ & PGA $=\mathbf{0 , 2}$ & $\mathbf{P G A}=\mathbf{0 , 3}$ & $\mathbf{P G A}=\mathbf{0 , 4}$ & $\mathbf{P G A}=\mathbf{0 , 5}$ & $\mathbf{P G A} \geq \mathbf{0 , 6}$ \\
\hline$S A$ & 0,8 & 0,8 & 0,8 & 0,8 & 0,8 & 0,8 \\
\hline$S B$ & 0,9 & 0,9 & 0,9 & 0,9 & 0,9 & 0,9 \\
\hline$S C$ & 1,3 & 1,2 & 1,2 & 1,2 & 1,2 & 1,2 \\
\hline$S D$ & 1,6 & 1,4 & 1,3 & 1,2 & 1,1 & 1,1 \\
\hline$S E$ & 2,4 & 1,9 & 1,6 & 1,4 & 1,2 & 1,1 \\
\hline
\end{tabular}

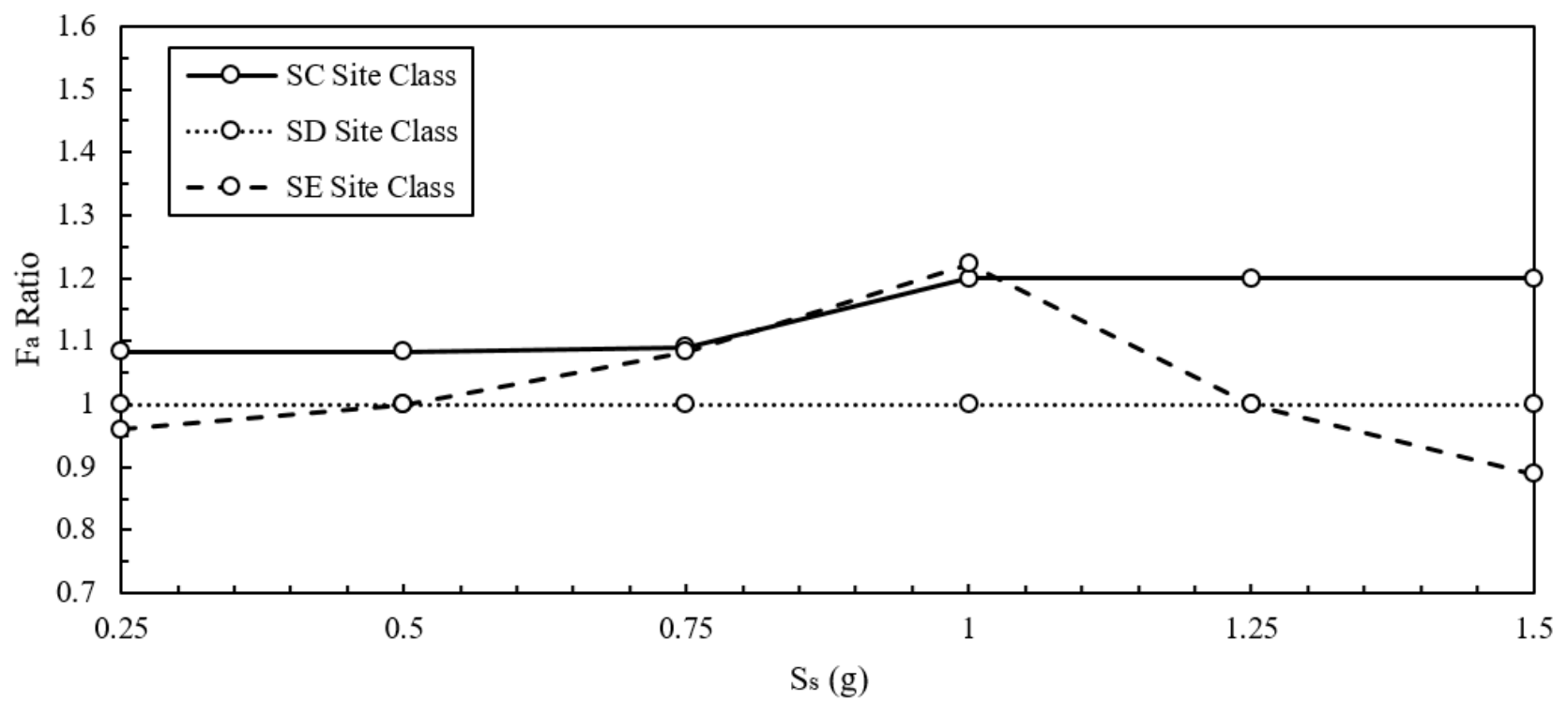

(a) 


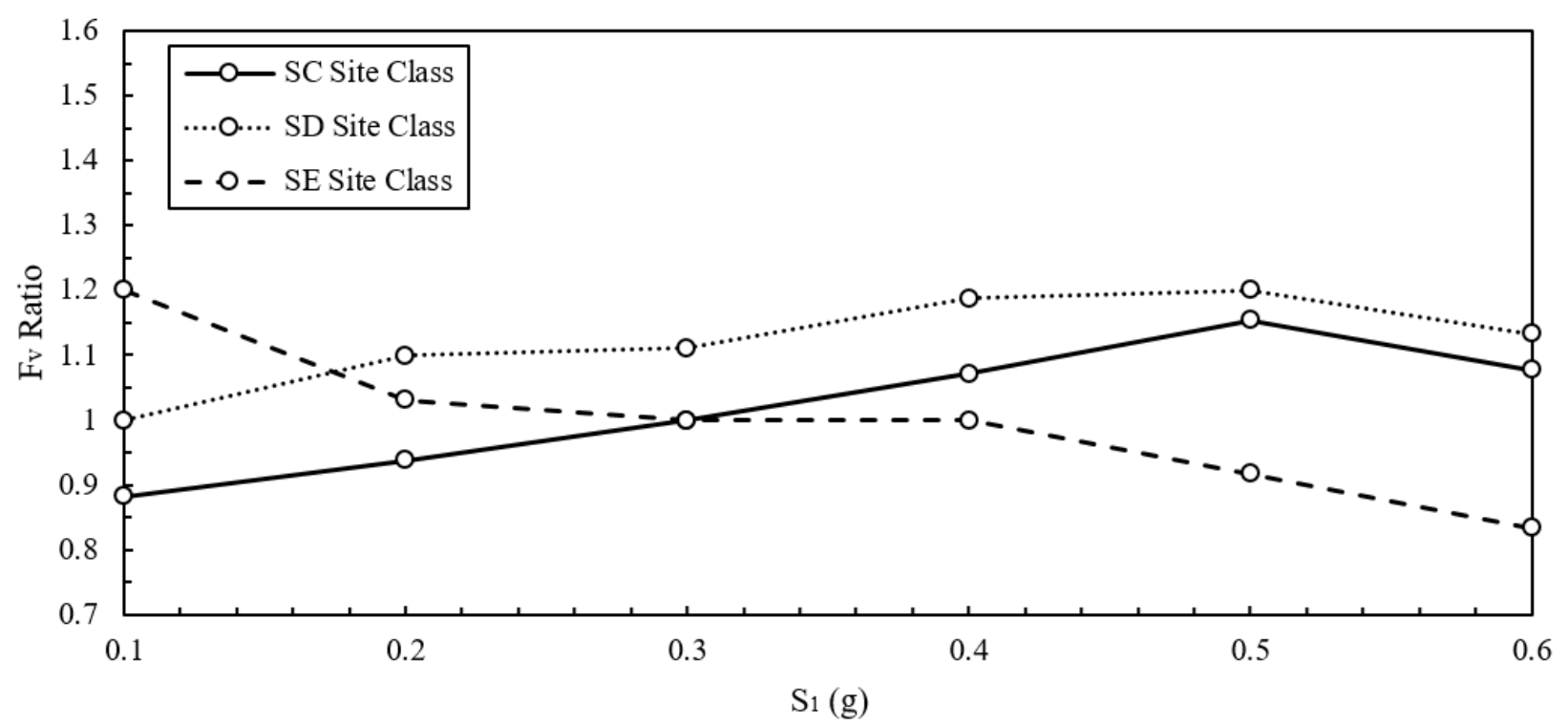

(b)

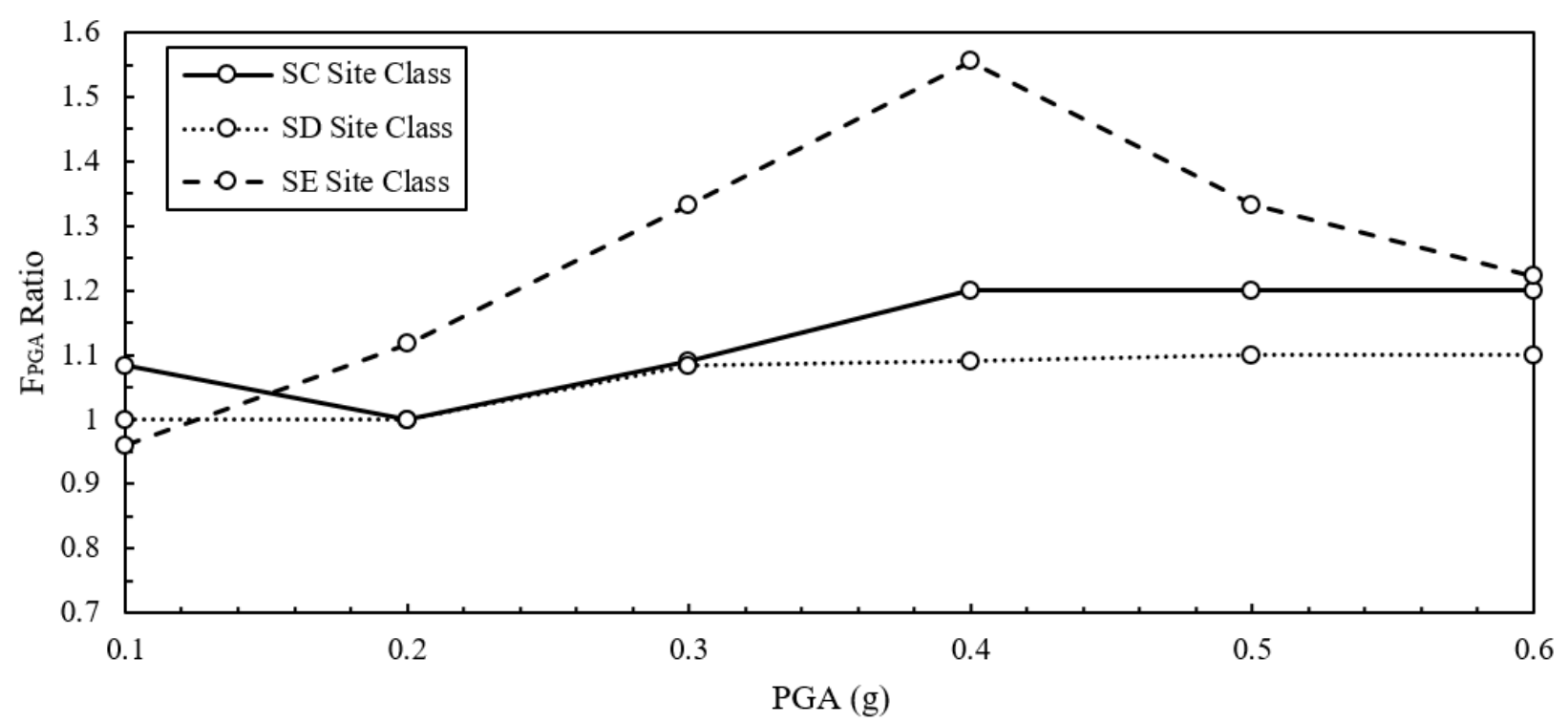

(c)

Fig. 7. Ratios of the updated site coefficient in SNI-1726-2019 divided by those in SNI-1726-2012 (a) $F_{a}$, (b) $F_{v}$, and (c) $F_{P G A}$

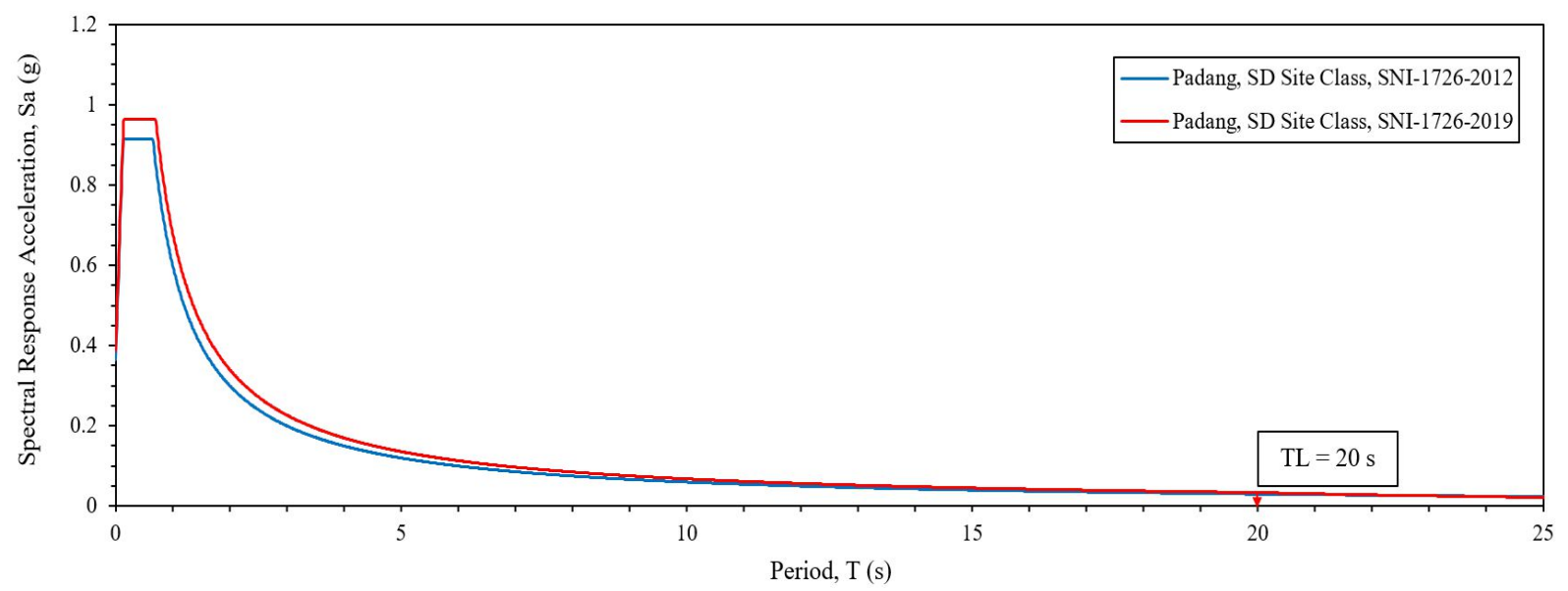

(a) 


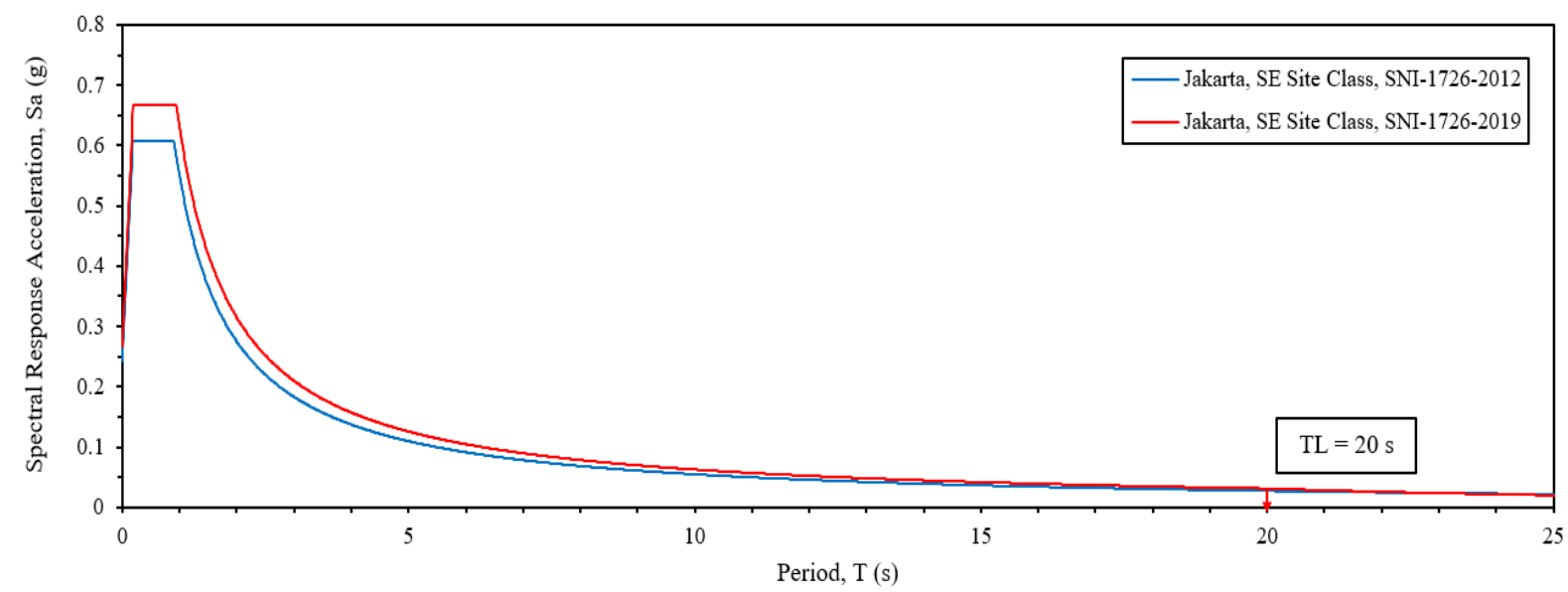

(b)

Fig. 8. Design Response Spectrum adopting SNI-1726-2012 and SNI-1726-2019 Parameters (a) Padang city and (b) Jakarta city

\section{Concluding Remarks}

The new 2017 Indonesian seismic hazard map has been revised with the major changes on the revised active fault database including the addition of newly identified active faults, revisions of the locations of previously known active fault traces, as well as improved estimates of maximum magnitudes and slip rates. The significant changes in the new Indonesian $\mathrm{MCE}_{\mathrm{R}}$ maps is the determination of the log-normal-standard-deviation $(\beta)$ and directivity factors. An Indonesian experts consensus was held in January 2018 to changes $\beta$ value from 0.7 to 0.65 , and adopt the directivity coefficient for maximum response of 1.1 and 1.3 for for short and 1-second period, respectively. New Risk-targeted ground motions (RTGM) in the form of $\mathrm{MCE}_{\mathrm{R}}$ maps for Indonesia have been developed as spectral response accelerations that represent $1 \%$ probability of building collapse in 50 years.

Evaluating the $\mathrm{RTGM}_{0.2 \mathrm{~s}}$ values, it is identified that most changes of $\mathrm{RTGM}_{0.2 \mathrm{~s}}$ values at several cities in Indonesia in the range of $-25.6 \%$ to $+19.3 \%$. Similar changes is also identified for updated $\mathrm{RTGM}_{1 \mathrm{~s}}$ values that is in the range of $-15.1 \%$ to $+23.9 \%$ compared with the values in prior to standard code. The highest decrease is identified in the Makassar city with changes of $-39.1 \%$ for $\mathrm{RTGM}_{0.2 \mathrm{~s}}$ value and $-28.4 \%$ for $\mathrm{RTGM}_{1 \mathrm{~s}}$ as high as $+35.5 \%$ which is identified in Palembang. Results of calculation show that risk coefficients for both spectral periods are more than $90 \%$ within the range of 0.9 to 1.1 , which is not significantly different from the previous RTGM study.

Values of short-period site coefficient $\left(\mathrm{F}_{\mathrm{a}}\right)$, longperiod site coefficient $\left(\mathrm{F}_{\mathrm{v}}\right)$, and PGA site coefficient at proposed SNI-1726-2019 have been updated with partial reference to ASCE 7-16. The updated values of $F_{a}, F_{v}$, and $F_{P G A}$ coefficient are shown in Table 3 to 5 . In addition to provide more realistic ground motions at periods $\mathrm{T}>4 \mathrm{sec}$ that would affect the design of tall buildings, the parameter $\mathrm{T}_{\mathrm{L}}$ was introduced in SNI-17262019.

The newly developed RTGM maps and site coefficient have been adopted in the New 2019 Indonesian Seismic Building Codes SNI-1726-2019.
The authors appreciate support by Dr. Luco for his valuable input and advice on the calculation of the new RTGM in this paper. Assistance by Ahmad Sulaiman for editing the paper is appreciated. Appreciation to PUSGEN for coordinating the development of hazard maps as input to the RTGM maps development. Various input by geotechnical team members of SNI-1726-2019 is also appreciated.

\section{References}

1. N.A. Abrahamson, K.O. Addo, G. Atkinson, B. Chiou, N.J., V. Silva, and R.R. Youngs, Ground Motion Characterization For BC-Hydro SSHAC Level 3 Study, Tenth U.S. National Conference on Earthquake Engineering, Fronties of Erathquake Engineering, IONCEE, Anchorage, Alaska, July 2124 (2014).

2. ASCE 7-10, 2010. Minimum design loads for buildings and other structures, American Society of Civil Engineers, 1 edition, ISBN-10:0784410852.

3. Boore D.M., Stewart J.P., Seyhan E. and Atkinson G.M., 2013. NGA-West 2 Equations for Predicting $P G A, P G V$, and 5\%-Damped PSA for Shallow Crustal Earthquakes.

4. Campbell, K.W. and Bozorgnia, Y., 2013. NGAWest2 Campbell-Bozorgnia Ground Motion Model for the horizontal Components of PGA, PGV and 5\%-Damped Elastic Pseudo-Acceleration Response Spectra for Periods Ranging from 0.01 to $10 \mathrm{sec}$, Pacific Earthquake Engineering Research Center, PEER Report 2013/6, pp.xii+75..

5. Chiou, B., and Youngs, R., 2008. An NGA Model for the Average Horizontal Component of Peak Ground Motion and Response Spectra, Earthquake Spectra, 24(1), 173-215.

6. Cornell, C.A., 1968. Engineering Seismic Risk Analysis, Bulletin of the Seismological Society of America, 58, 1583-1606.

7. FEMA, 2009. NEHRP Recommended seismic provisions for new buildings and other structures, FEMA P - 750 / 2009 Edition, Washington, D.C. 
8. Indonesian Standard Code, Earthquake Resistance Design for Buildings (SNI 03-1726-2002), National Standardization Agency, 2002.

9. Indonesian Standard Code, Earthquake Resistance Design for Buildings (SNI 03-1726-2012), National Standardization Agency, 2012.

10. Kircher, C., 2009. Basis for the New-Risk-targeted Ground Motion Maps, in COSMOS Annual Meeting Technical Session, Millbrae, CA, November 6 (2009).

11. Kircher \& Associates Consulting Engineers, 2015, Investigation of an Identified Short-coming in the Seismic Design Procedures of ASCE 7-10 and Development of Recommended Improvements for ASCE-7-16, Building Seismic Safety Council National Institute of Building Sciences, Washington, D.C.

12. Liel, A.B., Luco, Nicolas, Raghunandan, Meera, Champion, Casey P., 2015, Modification to RiskTargeted Seismic Design Maps for Subduction and Near-Fault Hazards, in 12th International Conference on Application of Statistic and Probability in Civil Engineering (ICASP), Vancouver, Canada, July 12-15 (2015).

13. Luco, Nicolas, Ellingwood, B.R., Hamburger, R.O., Hooper, J.D., Kimball, J.K., and Kircher, C.A., 2007, Risk-Targeted versus current seismic design maps for the conterminous United States, pp. 163175, in Structural Engineers Association of California 2007 Convention Proceedings, Callifornia.

14. Luco, N., Bachman, R.E., Crouse, C.B., Harris, J.R., Hooper, J.D, Kircher, C.A., Caldwell, P.J., and Rukstales, K.S., 2015. Updates to Building-Code Maps for the 2015 NEHRP Recommended Seismic Provisions, Earthquake Spectra Volume 31, Number S1, December 2015, pp. S245-S271.

15. Irsyam et al., 2017, National Center for Earthquake Studies (PuSGeN): Peta Sumber dan Bahaya
Gempa Indonesia Tahun 2017, ISBN: 978-6025489-01-3.

16. Sengara, IW., Masyhur, I., Merati, G.W., Sidi, I.D., Suarjana, M., Mulia, A., Yulman, M.A., Hutabarat, D., 2012. Development $M C E_{R}$ (Risk-Targeted Maximum Considered Earthquake) through Investigation of Hazard and Fragility Curve, Research Report - IMHERE Project B.2C FTSL, Institut Teknologi Bandung.

17. Sengara, IW., Masyhur, I., Sidi, I.D., Mulia, A., Asrurifak, M., Hutabarat, D., 2015. Development of Earthquake Risk-Targeted Ground Motion for Indonesian Earthquake Resistance Building Code SNI 1726-2012, in 12th International Conference on Application of Statistic and Probability in Civil Engineering (ICASP), July 12-15 (2015), Vancouver, Canada.

18. Sengara, IW., Yulman, M.A., Sumiartha, P., Mulia, A. 2016. Development on Risk-Based Seismic Design Criteria and Ground Motions for High-Rise Buildings in Jakarta, in the 3rd International Conference on Earthquake Engineering and Disaster Mitigation (ICEEDM). Bali, Indonesia.

19. Sidi, I.D., 2011. Research Report: Hazard Analysis and Probability Based Factor of Safety, Structural Engineering Division, Faculty of Civil and Environmental Engineering, Institut Teknologi Bandung, 2011.

20. Youngs, R.R., Chiou, S.J., Silva, W.J., \& Humphrey, J.R., 1997. Strong Ground Motion Attenuation Relationships for Subduction Zone Earthquakes, Seismol. Res. Lett., 68, 58-73.

21. Zhao John, X., Zhang, J., Asano, A., Ohno, Y., Oouchi, T., Takahashi, T., Ogawa, H., Irikura, K., Thio, H., \& Somerville, P., 2006. Attenuation Relations of Strong Motion in Japan Using Site Classification Based on Predominant Period, Bull. Seismol. Soc. Am., 96, 898 